\title{
REVOLUSI DECENTRALIZED EXCHANGE (DEX): TINJAUAN COMPETITIVE ADVANTAGE MELALUI ENTREPRENEURIAL ORIENTATION (EO) VIEW
}

\author{
Priscilla Levina \\ Made Siti Sundari \\ Henrycus Winarto Santoso \\ Fakultas Bisnis dan Ekonomika, Universitas Surabaya \\ Raya Kalirungkut, Surabaya, Indonesia 60293 \\ Email: priscillalevina00@gmail.com
}

\begin{abstract}
ABSTRAK
Revolusi dunia kripto yang semakin cepat menimbulkan banyaknya inovasi baru salah satunya Decentralized Exchange (DEX). DEX diciptakan sebagai solusi pengganti pihak ketiga dalam dunia finansial untuk transaksi yang lebih cepat, aman dan murah. Tujuan penelitian ini untuk menganalisis sistem revolusioner DEX serta analisis sumber keunggulan kompetitif bisnis DEX pada keunggulan kompetitif melalui sudut pandang Entrepreneurial Orientation (EO) di antara pesaingnya yaitu Uniswap, Pancake Swap, dan Sushi Swap. Objek penelitian DEX yang digunakan yaitu Shiba Swap yang menerapkan lima aspek dalam keunggulan kompetitif berupa tingkat pengembalian, komunitas terdesentralisasi, keamanan, kapitalisasi pasar, dan biaya transaksi yang rendah. Penelitian ini termasuk jenis penelitian kualitatif dengan paradigma post-postivisme dengan Simple Research Design (SRD). Pengujian data menggunakan deskripsi yang merupakan hasil observasi partisipasi sebagian. Hasil pengujian menunjukkan bahwa Shiba Swap memiliki keunggulan kompetitif yang lebih tinggi dari pada Uniswap, Pancake Swap, dan Sushi Swap
\end{abstract}

Kata Kunci: DEX, EO, Shiba Swap

\begin{abstract}
The rapid revolution of cryptocurrency has led to huge innovations: Decentralized Exchange (DEX). Decentralized Exchange (DEX) was created as a more efficient substitute solution for faster, safer, and cheaper transactions for third parties. This study aims to analyze the revolutionary DEX system and the source competitive advantage of competitive advantage through an Entrepreneurial Orientation (EO) view among its competitors which is Uniswap, Pancake Swap, and Sushi Swap. The object research of this study uses Shiba Swap, which has five aspects of competitive advantage: pyramid reward system, decentralized community, security guard, market capitalization, and low-cost transaction. This research uses qualitative research with post-positivism paradigm that using Simple Research Design (SRD). The data is examined by the description, which is the result of partial participation observations of social phenomena. The final result shows that Shiba Swap has higher Competitive Advantage than Uniswap, Pancake Swap, and Sushi Swap
\end{abstract}

Keywords: DEX, EO, Shiba Swap

DOI: https://doi.org/10.24123/jeb.v25i2.4837

\section{PENDAHULUAN}

Perkembangan bisnis internasional menjadi dasar terbentuknya pasar keuangan berskala internasional yang tumbuh dengan cepat (Buckley \& Casson, 2021). Salah satunya adalah pasar kripto yang menjadi pertukaran aset digital terdesentralisasi antara masing-masing mata uang kripto melalui teknologi ledger yang terdistribusi atau disebut blockchain (Svec et al, 2020). Pasar kripto muncul akibat adanya anomali yang terjadi dalam sistem keuangan tradisional dimana setiap orang yang ingin mengirim uang pada pihak tujuan harus melalui pihak ketiga. Perantara memainkan peran penting dalam menentukan biaya transaksi dan membantu pihak yang bertansaksi (Chen \& Bellavitis, 2019). Disinilah awal mula timbul gejala inefisiensi pada mekanisme dunia keuangan karena setiap transaksi akan membutuhkan biaya yang besar dan waktu yang lama. Hingga akhirnya, muncul teknologi kripto yang menggunakan sistem "Decentralized Exchange" (DEX) berbasis peerto-peer network akan membuat setiap individu dapat melakukan transaksi langsung tanpa perantara pihak ketiga. Sistem ini akan membawa revolusi baru dalam industri keuangan dimana dunia masa depan akan menciptakan kemudahan bagi orang dalam bertransaksi dengan cepat, efisien, biaya yang lebih rendah, dan setiap transaksi akan terjadi secara real time.

Ada beberapa hal yang menjadi pertimbangan yang dapat dilihat di Tabel 1: 
Tabel 1 Top 5 Exchange Swap Berdasarkan Market Capitalization

\begin{tabular}{lllll}
\hline Rank & \multicolumn{1}{c}{ Nama Koin } & Market Capitallization & Circulating Supply & Harga \\
\hline 10 & UniSwap (UNI) & Rp 173.497.032.363.689 & $587.267 .003,04$ & Rp 295.747,05 \\
29 & Shiba Inu (SHIB) & Rp 48.821.879.145.171 & 394.796 .008 & Rp 0,1236 \\
31 & Cosmos (ATOM) & Rp 40.623.904.560.633 & $217.640 .208,22$ & Rp 186.872,79 \\
35 & Pancake Swap (CAKE) & Rp 38.239.124.258.288 & $191.288 .756,23$ & Rp 200.726.9 \\
71 & Sushi Swap (SUSHI) & Rp 14.153.174.191.624 & 127.244 .443 & Rp 111.142,33
\end{tabular}

Sumber: coinmarketcrypto.com, diolah 2021

Berdasarkan Tabel 1, kapitalisasi pasar tertinggi adalah Uniswap sebanyak Rp173.497.032.363.689 sedangkan jumlah kapitalisasi pasar $\mathrm{Sh}^{1}{ }^{1}$ ba Inu berada dirutan ke-2 sejumlah Rp48.821.879.145.171. Hal ini dikarenakan harga uniswap jauh lebih mahal dari Shiba Inu, karena perhitungan market capitalization berasal dari harga dikalikan circulating supply. Shiba Swap terpilih sebagai objek penelitian karena merupakan salah satu terobosan inovatif dan luar biasa dalam dunia DEX. Adapun research gap dalam penelitian ini yaitu (1) sistem keuangan tidak hanya terdiri atas sentralisasi saja (Das Sein) namun terdapat sistem desentralisasi (Das Sollen); (2) banyaknya penelitian yang membahas strategi bisnis secara umum namun belum ada penelitian yang membahas strategi bisnis dalam industri keuangan khususnya di pasar kripto (research gap); (3) sejauh ini penelitian terkait strategi bisnis berfokus pada pengembangan marketing, distribusi, dan produk, namun melupakan ada faktor penting lainnya (theory testing); (4) banyak penelitian yang menyamakan keunggulan kompetitif dengan sumber keunggulan kompetitif dan kinerja, padahal keunggulan kompetitif diukur dari keunggulan relatif terhadap kompetitor (theory gap).

Keunggulan kompetitif berasal dari penciptaan nilai dan mekanisme insentif perusahaan (Mishra, 2017). Serangkaian kompetensi dalam suatu organisasi akan menghasilkan keunggulan kompetitif (O'Neill \& Brabazon, 2019). Penelitian lain menyatakan bahwa motivasi kerja juga dapat mempengaruhi keberhasilan organisasi (Al-Rfou \& Trawneh, 2017). Berdasarkan pendapat beberapa ahli terkait keunggulan kompetitif, diketahui bahwa terdapat banyak penelitian terkait menyamakan keunggulan kompetitif dengan sumber keunggulan kompetitif atau keunggulan kompetitif diartikan sebagai kinerja. Padahal seharusnya keunggulan kompetitif diartikan sebagaimana keunggulan kompetitif seharusnya. Sumber keunggulan kompetitif, kinerja, dan keunggulan kompetitif merupakan tiga aspek yang berbeda. Ma (2000) menjelaskan keunggulan kompetitif bersifat relational karena merupakan perbandingan antara suatu perusahaan dengan pesaingnya dari dimensi tertentu yang menjadi perhatian dalam kompetisi. Keunggulan kompetitif, sumber keunggulan kompetitif, dan kinerja merupakan tiga aspek yang berbeda namun saling bersifat mempengaruhi satu sama lain (Ma, 2000; Sigalas, 2015; Sigalas \& Papadakis, 2018).

Penelitian ini secara khusus akan membahas terkati sumber keunggulan kompetitif perusahaan yang terdiri atas dua hal yaitu internal dan eksternal. Sumber internal dan eksternal tersebut akan menjadi informasi bagi perusahaan untuk pengambilan keputusan. Berguna atau tidaknya informasi tersebut sangat tergantung dari seberapa besar pengetahuan yang dimiliki entrepreneur. Seorang entrepreneur harus memiliki jiwa yang mampu mewujudkan terobosan dan tindakan luar biasa yang berbeda dari pesaingnya dan bahkan mampu lebih unggul dari pesaingnya, sehingga akan terbentuk strategi yang lebih matang dan unggul. Oleh karena itu, seorang entrepreneur perlu melihat dari sudut pandang Entrepreneurial Orientation (EO). Penelitian ini akan menganalisis sumber keunggulan kompetitif Shiba Swap dilihat dari sudut pandang EO yang menghasilkan keunggulan kompetitif yang lebih baik dari pesaingnya yaitu Uniswap, Pancake Swap, dan Sushi Swap.

\section{METODE PENELITIAN}

Penelitian ini merupakan penelitian dasar yang menerapkan paradigma post-positivisme. Postpositivisme menyakini bahwa pengetahuan manusia di dunia tidak absolut namun parsial, bersifat dugaan, dapat ditantang, dapat dipalsukan bersifat sementara, dan terus berubah (Cohen et al., 2018). Post-positivisme menggunakan mekanisme deduktif dalam berpikir ilmiah yang diawali dari teori yang

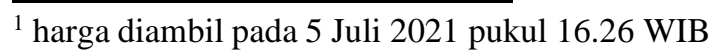


ada lalu dilakukan hipotesis, selanjutnya dilakukan observasi, dan hasil observasi akan di konfirmasi apakah realita yang terjadi sesuai atau tidak dengan teori (Bungin, 2020). Pada penelitian ini menggunakan desain penelitian Simple Research Design (SRD) dikarenakan penulis dapat merefleksikan pengalaman di lapangan dengan membuat penelitian sederhana. Berdasarkan tempat penelitiannya, penelitian ini menggunakan kombinasi field research dan library research. Pada field research, peneliti mengamati dan terlibat langsung dalam proses yang terjadi di lapangan. Data lapangan tersebut kemudian diteliti lebih lanjut menggunakan library research yang didapatkan dari whitepaper, buku, jurnal ilmiah, internet (website, press release, dan lainnya).

Sumber data primer yang digunakan pada penelitian ini yaitu aplikasi exchange swap Shiba Swap (https://shibaswap.com/). Sedangkan data sekunder diperoleh dari whitepaper, jurnal terdahulu yaitu literatur-literatur ilmiah terdahulu, pendapat para pakar, dan berbagai macam artikel. Metode penelitian yang digunakan adalah observasi partisipasi sebagian, dimana peneliti ikut terlibat berinvestasi dalam Shiba Swap namun hanya menggunakan fitur bury, stake, dan woof saja, sedangkan fitur lain seperti NFT dan Fetch tidak dapat digunakan karena adanya keterbatasan dana. Instrumen yang digunakan pada observasi yaitu lembar observasi yang berisi rating scale (untuk mengukur peringkat 5 aspek yaitu tingkat pengembaliam, keamanan, biaya, kapitalisasi pasar, dan komunitas). Metode pengujian validitas menggunakan teknik tiangulasi. Triangulasi hasil penelitian digunakan untuk mengakhiri pelaksanaan pengumpulan data dan menambah keyakinan bagi peneliti bahwa penelitian dan pengumpulan data telah dilakukan dengan prosedur yang sesuai (Bungin, 2020). Pengukuran yang digunakan dalam menentukan keunggulan sebuah exchange dibandingkan kompetitornya yaitu dengan menggunakan perbandingan secara tangible (numerik) yang melibatkan data, faktor lingkungan dan perspektif sosial yang ikut terlibat dalam penggunaan exchange tersebut.

\section{HASIL DAN PEMBAHASAN}

Shiba Swap didirikan oleh Ryoshi sebagai nama samaran. Ryoshi menciptakan sebuahkomunitas baru dengan perspektif yang unik dan meyakini bahwa melalui kekuatan kolektifdesentralisasi maka ia akan mampu membangun sesuatu yang jauh lebih kuat daripada sistem sentralisasi yang pernah dibuat. Para pengembang Shiba Swap mendedikasikan dirinya untuk membangun Decentralized Ecosystem (DEC). dengan adanya tiga token utama menjadi kunci utama bertumbuhnya Shiba Inu Ecosystem. Tujuan dari shiba swap yaitu menyediakan tempat yang aman bagi konsumen untuk berdagang kripto namun dengan system desentralisasi.

Shiba Swap terbukti telah mendobrak inovasi pada industri keuangan menjadi sebuah Decentralized Exchange (DEX) yang berbeda sekaligus lebih unggul. Revolusi Shiba Swap diciptakandari waktu sebelum Shiba Swap rilis (masih perencanan), saat Shiba Swap sudah rilis dan berproses, serta rencana masa depan proyek Shiba Swap. Sebelum Shiba Swap rilis, perusahaan Shibamembuat meme token Bernama Shiba Inu. Dalam waktu beberapa bulan, Shiba Swap mampu memiliki sumber keunggulan kompetitif yang menyamai

bahkan melebihi kualitas exchange lainnya. Hal ini telah mengalahkan teori Organizational Learning yang mengatakan bahwa semakin seseorang terjun lebih lama dalam bidang tertentu maka akan semakin

berpengalaman. Keunggulan ini dicapai karena Shiba Swap menerapkan sudut pandang Entreprenuerial Orientation(EO) dalam pelaksanaanya, sehingga banyak inovasi dan terobosan baru bahkan sebelum Shiba Swap dirilis. Berikut ini bentuk Entrepreneurial Orientation (EO) Shiba Swap:

1. Tokenomics of Shiba Swap: Shiba Swap terdiri atas 3 token utama yaitu Shiba Inu, Leashdan Bone, serta memiliki berbagai macam pair token

2. Fitur dalam Shiba Swap: terdapat beberapa fitur unik berupa bury, dig, woof, fetch, NFT, bonefolio dimana memiliki fungsi yang berbeda-beda

3. Shiba Swap Returns: memiliki multi reward system untuk setiap fitur yang ada

4. Shiba Inu Incubator: menaungi seluruh ekosistem dalam Shiba Swap

5. Shiba Swap Liquidity Provider Event: pemberian 1000 BONE per block yang dialokasikan di pool, setelah Liquidity Provider Event, maka supply BONE akan berkurang

6. The GRRR List: setiap pengguna dalam Shiba Army menginginkan keuntungan saat menanamkan modalnya dalam shiba swap.

7. Multisig Mode: Dompet multisig menyediakan kemampuan untuk mengambil tindakan dengan melindungi pengguna dari tindakan impulsif dan emosional.

8. RuffMap: Roadmap shiba swap cukup dirahasiakan untuk menjamin keuntungan yang dimiliki shiba swap 
tidak dicontoh oleh pihak luar

9. New Pairs Token: Tujuan Shiba Swap yaitu untuk mencapai 500+ pairs token selama tahun2021 dan hampir setiap minggu ditambahkan token baru.

10. Woofmap, Phase 2: Demi mewujudkan pengembangan ekosistem yang semakin lebih baik maka tim pengembang Shiba Inu menerbitkan fase 2. Visi utama dari Ryoshi yaitu untuk menciptakan Decentralized Financial Totality

11.ShibaNet: ShibaNet bekerja melalui jaringan NFT dan memiliki banyak fitur tambahan. Shiakan menjadi sistem pembayaran utama dalam ShibaNet sehingga pengguna dapat memiliki system pembayaran yang stabil.

12.Burn Token: Ryoshi telah membahas keputusan untuk membakar token Shiba agar dapatmeningkatkan harga dari Shiba itu sendiri menggunakan relect.

13.Shiba Inu Rescue Association: Ekosistem Shiba Inu yang diciptakan oleh Ryoshi tidakhanya dilandaskan hanya untuk memberikan keuntungan individu atau kelompok, namunbagaimana memberdayakan sebuah komunitas untuk menjadi lebih peduli pada sesame.

Berdasarkan bentuk inovasi Shiba Swap tersebut maka terciptalah sebuah keunggulan kompetitif. Shiba Swap lebih baik daripada pesaingnya dari lima aspek yaitu tingkat pengembalian, komunitas terdesentralisasi, keamanan, kapitalisasi pasar, dan biaya transaksi yang lebih rendah. Berikut ini adalah perbandingan tingkat pengembalian antar-exchange:

Tabel 2 Keuntungan yang Diterima Masing-masing Exchanges (Bunga Tunggal) ${ }^{2}$

\begin{tabular}{|c|c|c|c|c|c|c|}
\hline \multirow{3}{*}{ Keterangan } & \multicolumn{3}{|c|}{ Exchanges } & & & \\
\hline & \multirow[t]{2}{*}{ Uni Swap } & \multirow[t]{2}{*}{ Pancake Swap } & \multirow[t]{2}{*}{ shi Swap } & \multicolumn{3}{|c|}{ Shiba Swap } \\
\hline & & & & Shiba & Leash & Bone \\
\hline Investasi Awal & $\$ 1,000$ & $\$ 1,000$ & $\$ 1,000$ & $\$ 1,000$ & $\$ 1,000$ & $\$ 1,000$ \\
\hline APY & $2.99 \%$ & $56.33 \%$ & $8.01 \%$ & $94.59 \%$ & $140.52 \%$ & $354.60 \%$ \\
\hline $\begin{array}{l}\text { Keuntungan } \\
\text { per bulan }\end{array}$ & $\$ 2.46$ & $\$ 46.30$ & $\$ 6.58$ & $\$ 78.83$ & $\$ 117.10$ & $\$ 295.50$ \\
\hline $\begin{array}{c}\text { Keuntungan } \\
\text { per tahun }\end{array}$ & $\$ 29.87$ & $\$ 563.30$ & $\$ 80.07$ & $\$ 945.90$ & $\$ 1,405.20$ & $\$ 3,546.00$ \\
\hline
\end{tabular}

Sumber: Data Primer, 2021

Perbandingan keuntungan antar exchanges tertera di Tabel 2 yang menunjukkan bahwakeuntungan terbesar dalam satu tahun yang didapatkan dari bunga tunggal dimiliki oleh Shiba Swap di fitur bury bone dengan APY sebesar $354.60 \%$ atau sebesar $\$ 3,546$ per tahun atau $\$ 295.50$ per bulan. Sedangkan keuntungan terendah dengan bunga tunggal dimiliki oleh Uni Swap yang memiliki APY sebesar 2.99\% atau keuntungan per bulan sebanyak \$29.87 atau \$2.46 per bulan. Bila dilihat dari bunga majemuk maka Shiba Swap pada bury Bone tetap memiliki bunga tertinggi dan Uni Swap memiliki bunga majemuk terendah. komunitas dapat diartikan sebagai banyaknya pengguna yang percaya untuk menggunakan exchange tersebut. berikut ini adalah perbandingannya:

\footnotetext{
2 (1) Data diambil pada 3 Oktober 2021; (2) Bunga tidak memperhitungkan biaya seperti fee, pajak, dll.; (3) Bunga Tunggal dan Majemuk Uni Swap, Pancake Swap, dan Sushi Swap diambil dari https://www.stakingrewards.com/earn/uniswap/; https://www.stakingrewards.com/earn/pancakeswap/, dan https://www.stakingrewards.com/earn/sushi/, sedangkan untuk Shiba Swap diinverstasikan kembali setiap 6 bulan sekali (agar 66\% keuntungan yang dikunci selama 6bulan bisa digunakan untuk re-investasi).
} 
Tabel 3 Perbandingan Pengguna Uniswap, Sushi Swap, Pancake Swap, Shiba Swap

\begin{tabular}{lrccc}
\hline \multicolumn{1}{c}{ Tanggal } & Uniswap & Sushi Swap & Pancake Swap & Shiba Swap \\
\hline 4 Agustus 2021 & 260.203 & 61.225 & 651.430 & 610.541 \\
1 September 2021 & 267.020 & 67.951 & 720.405 & 646.219 \\
1 Oktober 2021 & 273.014 & 72.746 & 847.383 & 672.681 \\
\hline
\end{tabular}

Sumber: coinmarketcap.com, diolah 2021

Tabel 3 memperlihatkan jumlah pengguna selama 3 bulan dari 4 Agustus 2021 hingga 1 Oktober 2021. Namun bila melihat dari jumlah, maka pancake swap memiliki jumlah pengguna paling banyak dariketiga exchange lainnya, jumlah pengguna tertinggi kedua dimiliki oleh Shiba Swap yang diwakilkan oleh Shiba Inu, peringkat ketiga dimiliki oleh Uniswap, yang paling terendah dimiliki oleh Sushi Swap. Apabila mempertimbangkan lamanya exchange sudah berdiri, Pancake Swap sudah berdiri sejak September 2020, sedangkan Shiba Swap dibangun pada Juli 2021. Artinya dalam waktu 1 tahun, Pancake Swap mampu mencapai 847.383 pengguna, sedangkan Shiba Swap mampu mencapai 672.681 pengguna dalam waktu 4 bulan. Sehingga dapat dikatakan bahwa Shiba Swap mampu mencapai 3x lebih cepat daripada Pancake Swap. Dari segi keamanan, setiap exchange memiliki alat dan sistem keamanannya masing-masing yang dapat diukur melalui hasil audit:

Tabel 4 Hasil Audit Masing-masing Exchange

\begin{tabular}{lcccc}
\hline \multicolumn{1}{c}{ Security } & Uniswap & Sushi Swap & Pancake Swap & Shiba Swap \\
\hline Critical & 0 & 0 & 0 & 0 \\
Major & 0 & 2 & 1 & 8 \\
Medium & 3 & 3 & 1 & 1 \\
Low & 5 & 6 & 1 & 11 \\
Informational & 28 & 2 & 6 & 14 \\
\hline
\end{tabular}

Sumber: Certik Shield, 2021; PeckShield, 2021, diolah 2021

Melihat score di Tabel 4, yang paling sedikit mengalami isu keamanan yaitu Pancake swap. Peringkat kedua dimiliki oleh Sushi Swap, lalu peringkat ketiga Shiba swap, dan yang paling banyakyaitu Uniswap. Banyaknya isu tersebut, disebabkan karena adanya fitur, pembaharuan, project yang lemah dan memberikan celah bagi masalah lain untuk masuk ke dalamnya. Meskipun begitu, Shiba Swap mampu mengatasi permasalahan dengan cepat dan tepat waktu. Untuk segi kapitalisasi pasar, berikut ini adalah perbandingan kapitalisasi pasar masingmasing exchange:

Tabel 5 Perbandingan Market Capitalization Masing-masing Exchange

\begin{tabular}{clc}
\hline No & \multicolumn{1}{c}{ Exchange } & \multicolumn{1}{c}{ Market Capitalization (dollar) } \\
\hline 1 & Uniswap & 7.400 .000 .000 \\
2 & Sushi Swap & 4.920 .000 .000 \\
3 & Pancake Swap & 6.230 .000 .000 \\
4 & Shiba Swap & 38.632 .253 .800 \\
\hline
\end{tabular}

Sumber: coinmarketcap, 2021 *diambil tanggal 2 November 2021 pukul 12.41

Berdasarkan Tabel 5 dapat terlihat bahwa Shiba Swap memiliki kapitalisasi pasar tertinggi yaitu 38.632.253.800, sedangkan Sushi Swap memiliki kapitalisasi pasar terendah yaitu 4.920.000.000. Besarnya kapitalisasi pasar diawali pada hari pertama penerbitan Shiba Swap yang sudah memiliki total value locked (TVL) sebesar USD \$1.4 juta. Hal ini terus meningkat setiap harinya hingga pada 2 November 2021 sudah mencapai USD $\$ 517.250 .000$. Selanjutnya dari segi biaya dapat dilihat perbandingannya sebagai berikut. 
Tabel 6 Biaya per Transaksi Masing-masing Exchange

\begin{tabular}{llll}
\hline \multicolumn{1}{c}{ Exchange } & \multicolumn{1}{c}{ Blockchain } & Jaringan & \multicolumn{1}{c}{ Biaya per transaksi } \\
\hline Uniswap & Ethereum & ERC-20 & $0,3 \%$ dari poolfees \\
Sushi Swap & Binance Smart Chain & BEP-20 & $0,3 \%$ setiap transaksi swap \\
Pancake Swap & Ethereum & ERC-20 & $0,2 \%$ setiap transaksi swap \\
Shiba Swap & Ethereum & ERC-20 & Bury (stake) : \$11.26, Bury (unstake) : \\
& & & \$12.05, Dig : 0,001 ETH \\
\hline
\end{tabular}

Sumber: berbagai sumber diolah, 2021

Biaya per transaksi yang terdeskripsi pada Tabel 6 memberikan pandangan bahwa Uniswap, SushiSwap, dan Pancake Swap memberikan biaya menggunakan persentase, sedangkan Shiba Swapmenggunakan nominal. Hal ini dapat menjadi keuntungan bagi pihak yang berinvestasi dengandana yang banyak, namun pihak yang memiliki dana investasi yang kecil akan sangat dirugikan.Untuk merangkum semua keunggulan kompetitif masing-masing exchange, maka akan dilakukanranking score pada setiap aspek melalui grafik labalaba:

Gambar 2 Perbandingan Grafik Laba-laba Uniswap, Sushi Swap, Pancake Swap, dan Shiba Swap

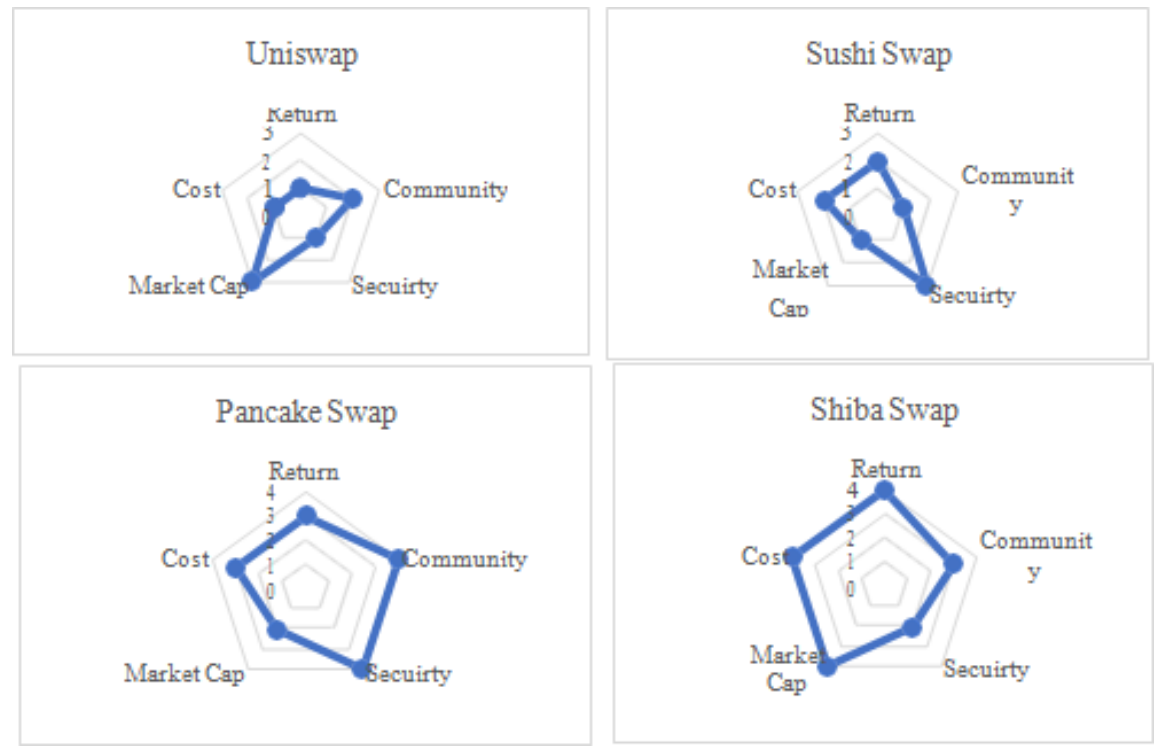

Sumber: Data Primer diolah, 2021

Grafik jaring laba-laba setiap exchange ditunjukkan oleh Gambar 2, dimana semakin tinggi peringkat maka akan mendapatkan nilai yang lebih besar. Konteks gambar diatas memiliki pengandaian bahwa peringkat 1 memiliki nilai 4, peringkat 2 memiliki nilai 3, peringkat 3 memilikinilai 2, dan peringkat 4 memiliki nilai 1 . Oleh karena itu, inti lingkaran merupakan nilai yang palingkecil dan nilai yang besar berada pada lingkaran paling luar. Pada grafik laba-laba terdapat lima aspek utama yaitu return, community, security, market capitalizaiton, dan cost. Dari keempat gambar diatas, Shiba Swap memiliki gambaran yang paling luas. Artinya nilai setiap aspek yang dimiliki Shiba Swap sangat besar dibandingkan dengan exchange lainnya, yang secara tidak langsung menandakan bahwa Shiba Swap memiliki keunggulan kompetitif lebih tinggi dibandingkan kompetitornya. Sedari awal, Ryoshi ingin menciptakan suatu terobosan baru dalam dunia kripto dengan memberikan mekanisme staking, swap dan farming sekaligus dalam satu exchange yang memberikan utilitas bagi pengguna maupun pengembangnya.

Sudut pandang Shiba Swap dalam merancang sebuah strategi didasarkan pada inovasi, lingkungan dan keingginan pengguna. Ide proatktif dan peningkatan kualitas dari token maupun Shiba Swap membuat Shiba Swap memiliki keunggulan yang tidak terduga dan sulit ditiru. Setiap strategi Shiba Swap menciptakan utilitas lebih bagi penggunanya, sehingga akan semakin menarikbanyak orang yang ingin berinvestasi dalam Shiba Swap seperti NFT, bury, dan dig yang menawarkan keuntungan luar biasa tinggi bila dibandingkan dengan DEX lainnya. pengembalian yang tinggi tersebut memiliki proses penyaluran yang panjang dan telah ditunjukkan pada gambar sebelumnya dan telah diaudit oleh Certik, sehingga tidak bisa lagi dikatakan 
penipuan. Penerapanstrategi memiliki pengaruh terhadap keunikan produk perusahaan dan posisi pasar yang ditentukan oleh keunggulan kompetitif. Berikut ini adalah roadmap strategi Shiba Swap terhadap keunggulan kompetitif:

\section{Gambar 3 Road Map Strategy Shiba Swap terhadap Keunggulan kompetitif}

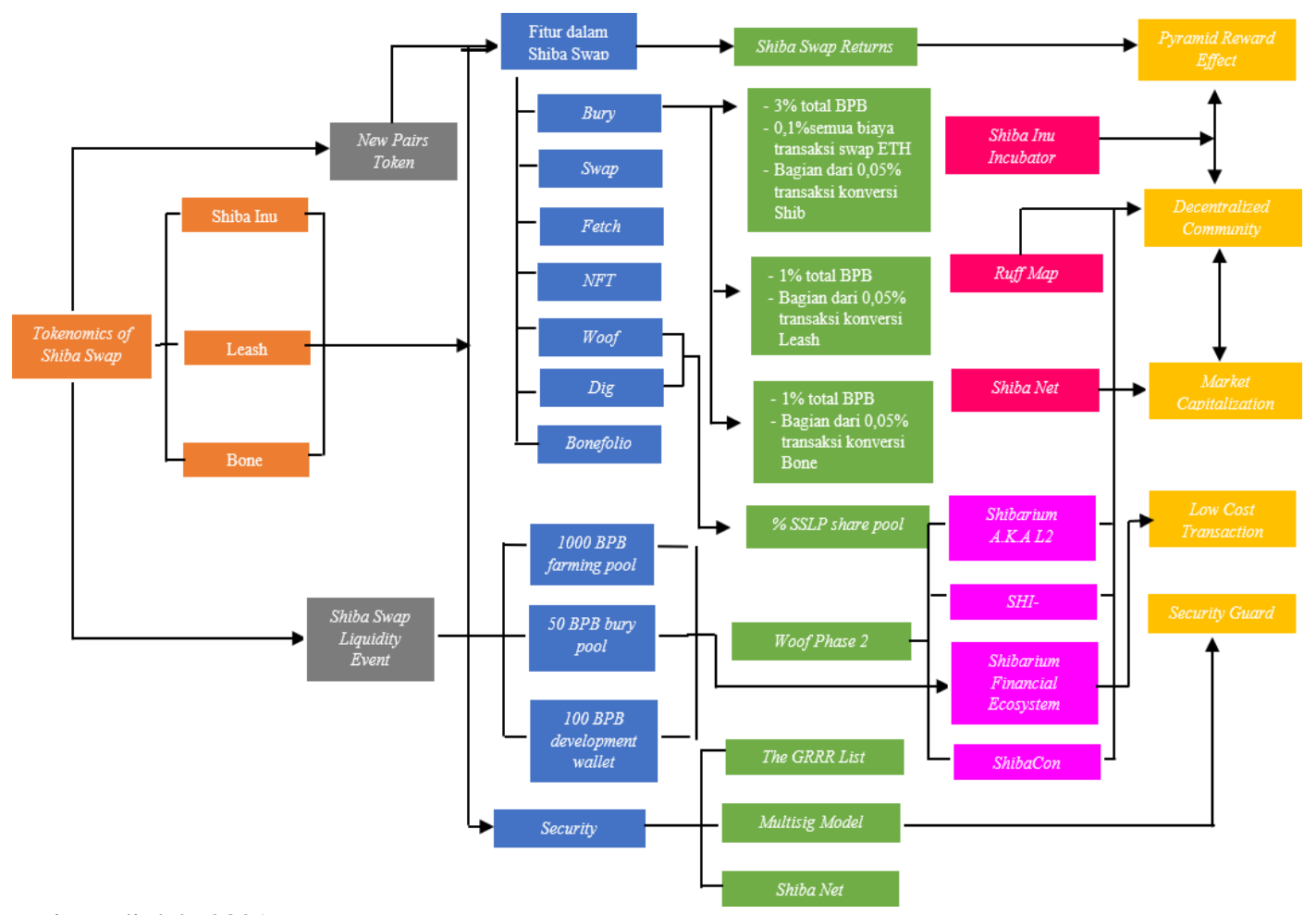

Sumber: Data Primer diolah, 2021

Peta aliran strategi yang memberikan keunikan pada fitur tertentu memiliki tujuan yang ingin dicapai. Gambar 3 memperlihatkan awal mula Shiba Swap diciptakan melalui tiga token utamayaitu Shiba Inu, Leash dan Bone. Seiring berjalannya waktu token tersebut bertambah melalui newpairs token maupun token lainnya seperti Treat dan Doggy Dao. Token baru tersebut yang kemudian dimasukkan ke dalam setiap fitur dalam Shiba Swap berupa bury, dig, swap, fetch, NFT, woof, dan bonefolio. Dari seluruh fitur yang ada, terdapat 3 fitur yang menghasilkan keuntungan yaitu bury, dig, dan woof. Setiap fitur memiliki mekanisme yang berbedabeda untuk menghasilkan keuntungan. Keuntungan yang dihasilkan pada akhirnya menjadi faktor terbentuknya lima aspek keunggulan kompetitif di Shiba Swap yaitu pyramid reward return, decentralized community, security guard, market capitalization, dan low-cost transaction. Oleh karena itu, telah terbukti bahwa sumber keunggulan kompetitif yang terdiri atas internal dan eksternal akan menjadi fondasi untuk pengetahuan seseorang atau kelompok. Pengetahuan tersebut sebagai landasan untuk melakukan strategi bisnis agar visi dan misi perusahaan bisa terlaksana. Dalam menjalankan strategi, dibutuhkan EO di perusahaan agar mencapai keunggulan kompetitif yang lebih unggul daripada pesaingnya.

\section{KESIMPULAN DAN SARAN}

Dunia kripto telah berevolusi mengikuti perkembangan zaman dan banyak pengembang serta bisnis yang berlomba-lomba untuk menyelesaikan permasalahan kripto yang ada seperti skalabilitas, interperabilitas, dan ketahanan. Salah satu yang menarik dalam dunia kripto yaitu menggunakan sistem decentralized finance yang yang salah satunya berupa decentralized exchange. Decentralized exchange merupakan tempar pertukaran token kripto yang bersifatterdesentralisasi dan transparan, artinya setiap orang yang berada pada exchange tersebut dapat mengetahui jumlah dana yang masuk dan keluar. Keuntungan decentralized exchange dibandingkan dengan centralized exchange yaitu adanya sifat transparansi dan keterbukaan informasi yang diberikan pada setiap pengguna, serta para pengguna dapat melakukan validasi dankontrol terhadap transaksi yang dilakukan oleh pengguna lainnya sehingga akan menciptakan check and balance antar pengguna. Berikut 
ini adalah analisis revolusi yang dilakuakn Shiba Swap dalam dunia decentralized exchange, strategi yang diterapkan Shiba Swap, dan bagaimana keterkaitan strategi bisnis terhadap keunggulan kompetitif:

1. Revolusi yang dilakukan Shiba Swap tidaklah mudah dan membutuhkan waktu yang cukup lama untuk membangun mekanisme yang luar biasa. Sistem ini awalnya dirancang dengan memperluas pangsa pasar terlebih dahulu melalui penerbitan token Shiba Swap, setelah itu baru diciptakannya Shiba Swap sebagai salah satu terobosan yang mampu meningkatkan utilitas proyek Shiba. Produk Shiba Swap sendiri dibuat untuk memberikan keuntungan bagi pengguna dan pengembangnya. Pengembang memperoleh manfaat dari persentase transaksi swap Ethereum dan Shiba, sedangkan pengguna mendapatkan persentase keuntungan sesuaidengan fitur yang dipilihnya baik itu bury, dig atau NFT.

2. Entreprenurship Orientation di Shiba Swap dimiliki dari adanya pengetahuan yang dimiliki entrepreneur untuk mengolah sumber keunggulan kompetitif dengan baik. EO dapat berupa sikap inovasi, proaktif, dan pengambilan resiko yang dimiliki oleh Shiba Swap. Demi terwujudnya EO, membutuhkan komitmen dan integritas yang tinggi dari semua pihak baik pengembang maupun komunitas agar mampu mencapai kesuksesan Shiba Swap.

3. Terbentuknya keunggulan kompetitif Shiba swap yang lebih unggul dari pesaingnyadipengaruhi oleh 5 aspek utama yaitu tingkat pengembalian, desentralisasi komunitas, keamanan, kapitalisasi pasar, dan biaya transaksi yang murah. Dari kelima aspek tersebut, melalui analisis jaring laba-laba maka diperoleh Shiba Swap memiliki keunggulan yang lebih baik dari para pesaing lainnya yaitu Uniswap, Pancake Swap dan Sushi Swap yakni lebih cepat, lebih banyak komunitas, lebih aman, lebih luas pangsa pasarnya, dan lebih murah biayatransaksi.

Terlepas dari itu semua, penelitian ini hanya menggunakan satu objek penelitian saja, namuntidak meneliti secara mendalam mengenai decentralized exchange lainnya. Data yang diperoleh pada penelitian didasarkan pada informasi para pengembang dan data yang terdapat pada platform Shiba Swap, namun kurang memberikan eksperimen secara langsung bagaimana keuntungan dapat dirasakan secara nyata oleh pengguna selama periode waktu tertentu.

Keterbatasan ini dapat menjadi peluang bagi penelitian berikutnya dimana penelitian ini dapatdijadikan dasar untuk mempelopori penelitian lainnya yang terkait dengan dunia decentralized finance dan decentralized exchange. Bagi para decentralized exchange lainnya, Shiba Swap dapat menjadi pemicu untuk menciptakan decentralized exchange lain yang lebih baik. Secara tidak langsung, Shiba Swap telah memberikan bukti bahwa komunitas mampu memberikan dampak yang cukup besar bagi sebuah bisnis. Selain itu, Dalam berinvestasi pada exchanges, para investordiharapkan dapat bersikap bijak serta melakukan manejemen keuangan dan manajemen resiko untuk mendapatkan hasil pendapatan yang maksimal.

\section{DAFTAR PUSTAKA}

Buckley, P., \& Casson, M. (2021). International Business Research. INternational Business Review, Vol 30 (Issue 2).

Bungin, B. (2020). POST-QUALITATIVE SOCIAL RESEARCH METHODS: Kuantitatif-Kualitatif-mix Methods Positivism-Postpositivism-Phenomenology-Postmodern, Filsafat, Paradigma, Teori, Metode dan Laporan (Vol. Edisi Pertama). Jakarta: Kencana.

Calcaterra, C., \& Kaal, W. (2021). Decentralized Finance (DeFi). Finance: SSRN Electronic Journal. [Diakses: 10 Juli 2021]. Pada https://www.certik.org/projects/shib

Chen, Y., \& Bellavitis, C. (2019). Blockchain Disruption and Decentralized Finance: The Rise ofDecentralized Business Models. Elsevier BV.

Cohen, J. (2019). Between Truth and Power: The Legal Constructions of Informational Capitalism. New York: Oxford University Press.

CoinMarketCap. Shiba Inu, Leash, Bone. [Diakses: 2 November 2021]. Pada https://coinmarketcap.com/

Dobrynskaya, V. (2020). Is Downside Risk Priced in Cryptocurrency Market? SSRN ElectronicJournal.

Ma, H. (2000). Competitive Advantage and Firm Performance. Competitiveness Review: An International Business Journal Incorporating Journal of Global Competitiveness, 10(2), 15-32.

Peck Shield. Peck Shield / Publications. [Diakses: 2 November 2021]. Pada https://github.com/peckshield/publications/blob/master/audit_reports/PeckShield-Audit-ReportSushiSwap-v1.0.pdf

Shiba Swap. (2021). Shiba Swap.com. [Diakses: 12 Juli 2021]. Pada https://shibaswap.com/ 
Sigalas, C. (2015). Competitive advantage: The known unknown concept. Management Decision, 53 (9), 2004-2016.

Sigalas, C., \& Papadakis, V. (2018). Empirical Investigation of Relationship Patterns between Competitive Advantage and Superior Performance. Journal of Strat4egy and Management,11(1), 1-32.

Staking Rewards. (2021). Staking Rewards Pancake Swap. [Diakses: 4 Oktober 2021]. Pada https://www.stakingrewards.com/earn/pancakeswap/

Staking Rewards. (2021). Staking Rewards Sushi Swap. [Diakses: 4 Oktober 2021]. Pada https://www.stakingrewards.com/earn/sushi/

Staking Rewards. (2021). Staking Rewards Uniswap. [Diakses: 4 Oktober 2021]. Pada https://www.stakingrewards.com/earn/uniswap/

Sushi.com. (2020). Sushi. From Be A DeFI Chef with Sushi.

Svec, J., Foley, S., \& Aspris, A. (2020). Market structure of cryptocurrencies. Cryptocurrency andBlockchain Technology, https://doi.org/10.1515/9783110660807-006.

Uniswap.org. (2020). Uniswap. From Decentralized Trading Protocol. 